\title{
O ESPAÇO E OS OBJETOS EM QUINCAS BORBA
}

\author{
Cassiana Lacerda Carollo * \\ "Se a palavra "existir" significa ser percebido com evidêr." \\ cia no centro do campo da consciência, o interesse pelas coisas, \\ pelos objetos, quase näo se manifesta antes do Século XIX". \\ (Moles \& Wohl)
}

\section{Proposição}

A obra de Machado de Assis ocupa lugar privilegiado não só em relação a sua época como na evolução da literatura brasileira, pela consciência de funcionalidade que integra seu processo de feitura.

Tal pressuposto pode justificar a pertinência da caracterização de sua técnica de preenchimento do espaço narrativo, como não discritiva ou, em que a descrição assume o papel de instrumento discreto, quando não de um signo unívoco.

Por sua vez, o horror ao pitoresco como tônica de sua ficção, torna o leitor predisposto a situar a causa secreta de qualquer digressão, principalmente de caráter descritivo, na tentativa de incorporá-la à rede causal através de um ponto de vista participante. Daí, se falar em cenário causal em Machado de Assis, com suas decorrentes implicações de busca do equivalente social ou psicosocial.

Se para Lukáes "o dilema participar ou observar (narrar ou descrever) é uma questão ligada à posição do escritor em face da vi-

- Cossiana Lacerda Carollo, Doutoranda ns Universidade de São Paulo publiea na revis10 Letras desdo 1969. Colaboradora de Arquivas (Curitiba) e de outros rovistas especializadas exerce as funçōes do Professora de Literatura Brasileipa de Diretora do Sstor de Ciéncias Humanas, Letras - Artes da Universidade Federal do Parań. 
da"1, o tratamento e o grau de funcionalidade do espaço e dos objetos eim Quincas Borba, podem ser consideradas categorias mediadoras possíveis para a interpretação da ideologia machadiana.

Nossa análise do papel assumido pelo espaço e objetos, explorando desde a consciência de co-realidade, simetria do espaço narrativo até a construção do(s)s espaço(s) e objetos no nivel da cadeia horizontal da ação e sua função na estrutura narrativa será, portanto, uma tentativa de demonstrar que Quineas Borba reflete a tensão entre o modelo de vida romântica e o desejo de instalação ou do sistema de oposições apontado for Moles", do honem cheio de gemutlichkeit e de previsibilidade.

Será a tarefa de revelar a compreensão machadiana para o valor que assume o objeto na sociedade burguesa, em que o nível na escala social tem como pressuposto um inventário de objetos cuja falsidade ou distorção de funcionalidade faz com que tomem a dimensão de kitseh.

Pretendemos, através da análise, demonstrar que o inventário dos espaços e objetos nesta obra, que explora ainda uma vez o tema do interesse no jogo de vitória", sistematizado no refrão "ao vencedor as batatas", fora do variável desenvolvimento de uma sociedade, comporta o lugar do indivíduo nesta sociedade em que o objeto ganha o estatuto de sinédoque do sujeito.

Será a tarefa de comprovar a observaçāo de Raymundo Faoro quando este assim caracterizou a dialética objetividade/subjetividade na ficção machadiana:

"Certas realidades, corporificadas em coisas, sentem e querem, por efeito da ilusão patética que anima os seres inanimados. Na guerra das coisas está o conflito dos homens, simbolizados, materializados e objetivados (...) o mundo exterior se realiza e se desenvolve fora do homem. como se suas peças macaqueassem o homem, para o efeito de espancar o subjetivismo, Objetiva-se o mundo, nas dobras do objetivismo, infiltra-se e escor-

I LUKACS, George. Narrar ou descrever. In; - Ensaios sobre literatura. Rio de Janciro, Civilizą̧āo Brasileiro, 1968. p. 99.

2 MOLES, A. \&, WAHL, Eberhard. Kitsch e o obieto. in; MOLES et alii. Semiologia dos cbjetas, Petrópolis, Vozcs, 1972 p. 161.

3 Mistloso Câmera cm seus Enzaies machadianes aproxima o lema de Quineas Borba du tacrij do cepacu vitel. 
rega a ação humana, colada às próprias coisas, como manifestações destas, friamente"

\section{O espaço do livro}

Cogitações em torno da consciência da escrita em Machado de Assis vêem se tornando lugar comum, notadamente entre aqueles preocupados com a defesa da intransitividade do signo. Porém. se a consciência do escritor em relação ao espaço da escrita é um processo de certa forma evidente quando se analisa os casos explicitos de enunciação enunciada, o trabalho torna-se mais complexo nos casos de metalinguagem corrigida pela sensação do referente, nas situaçōes em que a consciência do processo do discurso, através da relação narrador/narratório, se desenvolve a partir de procedimentos encobertos.

A polifonia do narrador nas Memórias Póstumas de Brás Cubas e em D. Casmurro pode ser situada com certa dose de evidência (graças, sobretudo à primeira pessoa narrador-personagem) quando da operação autor real/autor implícito, leitor real/leitor implícito.

No caso de Quincas Borba, o leitor "real" é também enunciado ao longo do discurso, porém sua presença já não é tão manifesta a ponto de encontrarmos apenas seis referências diretas a êles.

Acrescente-se que das seis referências, apenas duas são qualificadas: "paciente leitora", "leitor curioso", não havendo possibilidade de uma análise do tipo a ser aplicado em D. Casmurro, por exemplo, onde se pode inventariar as várias categorias de leitor, seja por classe social, público, expectativa de leitura, etc.

O processo de diálogo narrador/narratório déve ser estudado em Quincas Borba, sobretudo nos componentes internos que instauram a situação de discursos: os deícticos.

Nesta obra, além do caráter coloquial de relacionamento eu-tu, - emprego da primeira pessoa do plural, responsável pelo afloramento dos protagonistas da enunciação ("nosso amigo", "nosso homem", "vamos vê-lo...), das orações interrogativas, dos advérbios (aqui, agora, aquele) evidenciam a situação do discurso no seu mecanismo interno.

Vale dizer, os deicticos são componentes estratégicos para que

4 FAORO, Roymundo. Machado de Assis: a pirâmide e o Irapásio. Säo Paulo, Cia. Editora Nacional, 1974. p. 41.

5 Vide pags. 115, 141, 218, 235, 273, da ediçāo citada nas referências. 
esta situação se apresente pela alusão, como se o leitor já possuísse a informação, resultando na reciprocidade de mensagens.

Também os termos modalizadores (talvez, pode ser etc.) incidem no sujeito que os enuncia além de serem básicos na relativização da previsibilidade de leitura.

Assim, fica em segundo plano, a caracterizaçāo deste procedimento como indices de preocupação com a economia narrativa, pelo que significam como marcas do processo de enunciaçāo:

"Sobejam exemplos, mas basta um cantozinho que ouvi em criança e aqui the dou em duas palavras" (p. 269) "Ainda não disse, porque os capífulos atropelaram-se debaixo da pena (271). "Mas vendo a morte do cão narrada em um capítulo especiai, é provável que me perguntes se este, se o seu defunto homônimo é que dá título ao livro, e porque antes um que outro, questāo prenhe de questōes: que nos levariam longe". (p. 235).

O convite à carticipação do leitor, por sua vez, aparece numa tipologia de discurso centrada no receptor, porém acaba por reafi:mar o autor to:nado "real" diante das indicaçōes do livio se fazendo, como nos exemplos em que a obra é materializada espacialmente pela consciência das partes, remissōes a capítulos, referência a outros espaços literários, questionamento do método adotado para a titulação dos capítulos, etc ${ }^{6}$.

Os comentários sobre a obra se fazendo, a consciência do referente, em casos de metalinguagem corrigida (a sombra da sombra de uma lembrança grotesca" $p$. 178) são procedimentos que acentuam o sujeito e a matéria do discurso, apesar da alusão criar a impressão de reciprocidade eu/tu privilegiando o receptor (Essa é reflexão do leitor (p. 218) "Calúnia" do leitor (p. 235).

Casos há em que a correção incide na matéria enunciada, como na passagem em que se dá a "intriga" provocada pelas desconfianças em torno da "Rua da Harmonia", "écart" altamente significativo no processo de desmascaramento das personagens, mas que o autor

6 "Este Ouinces Berba, ee zesso me fizesie o favef de ler as Memórias Póstumas de Bris Cubas" (0. 115 ) "No capitulo $X$ deste livre" (p. 175) "exceutando o gesto do capi. tulo $X X X V$ (p. 195). "A fiths cstará ainda qual a deixamos no cap. XLIII" "confessou a mulher na morte de Santa Tereza". capitula C" (D. 226). "ecemo ficeu expresso na capitu. 10..." (0. 296). "E de saber que linham decorrido oito meses desde o psinsipio do capitulo anterior" (D. 193) e ainda nos capítulos CXII. tal fosse a métedo deste livro eis aqui um titulo que explicaria 1udo" (o. 243). 
procura encobrir reforçando a aparência de digressão, o que irá provocar o distanciamento entre o percurso das personagens em relação ao da matéria narrada e sua construção:

"Se falou em Rua da Harmonia por sugestão do bairro donde vinham".

"Não era razão para que eu cortasse o episódio ou interrompesse o livro" (p. 235).

Trata-se de romper com determinada interpretação pela marca do lugar do discurso, instaurando a relativização pela recusa de um sódigo ${ }^{7}$ ou estabelecendo a diferença.

O lugar do emissor torna-se um lugar limite, pelo desnudamento do mecanismo articulador através da descontinuidade com a coisa mostrada como tal, tornando-se secundário neste tipo de discurso - questionamento da verossimilhança empírica.

Este procedimento é, como observa Greimas ${ }^{8}$, do tipo que sublinha a heterogeneidade de isotopias com as quais nos defrontamos quando se trata de dialética normal/anormal.

Daí nos parecer pertinente a colocação de Dirce Riedel" do a referida ensaísta, aproxima tal marcação do lugar do discurso de um projeto análogo ao da "loucura", no que esta comporta de recusa a um código'o.

O que nos leva, ainda uma vez, a vincular a consciência do espaço da escrita à consciência da realidade, quando esta é concebida pela recusa da instauração de um discurso ideológico, que como tal esconde a diferença entre o manifesto $e$ o dissimulado.

\section{A vitória da simetria ou a simetria da vitória}

O estudo do tratamento machadiano dado à questão da simetria, ocupa lugar de destaque pela vinculação com sua concepção simétrica de existência sendo a vida para ele "assim mesmo, uma repetiçāo".

7. É caso de evocar o concelto de obra formulado por Roland Barthes em Roland Barthes par Roland 8arthes: "La Dexa c'est l'Opinisn publique, l'Esp:it majoritairc, le Ccnsenst's petit bourgeois, la Voix du Natural, la Violence du Préfuge". On peut appeler doxologie (mor de Leibnitz) toute manière de parter adaptée à l'apparence, à l'opinion ou à la pratique". p. 51. A partir daf o lugar do emissor estará ligado ao centrole da imagem cu frase que acredita que outros esperam.

.8 GREIMAS, A. J. Semintica estrulural. 5ão Paulo, Cultrix, 1973, p. 95.

9 RIEDEL, Dires Corros. Messfors, o espelho de Machado de Assis, Rio de Janciro, Livraria Francisco Alves, 1974.

10 Confira.se: "O discurso do "razāo" sarve aos interesses de equilibrio social, êle se marea. no lugar do édigo (...). Num certo sentido a leucura serve para mostrar qus a estruturaçāo institucional a pessoal num discurso social nāo eumpre nas relaçōes, coneresas suas imagens de representação social ${ }^{\mu .}$. (Antonio Sergio Mendonça. Par uma tooris do simbálico. Petrópolis, Vozes, 1974 p. 85. 
Barbacena, espaço inicial da carência, será o palco da degradação final, após breve suspensāo da carência durante a experiência no Rio.

Esta visão simétrica que vai do espaço inicial ao final seria simplista nāo fosse ela responsável pelo jogo de perspectivas.

Rubiāo seduz Quincas Borba, é seduzido por Palha e Sofia num processo em que, na estrutura do interesse, a troca é o elemento relativizador do uso.

Evidentemente, na perspectiva do louco temos a consagração sob forma de coroamento, enquanto que a mesma situação, na perspectiva de Palha e Sofia, corresponde à degradação de Rubiāo e ao consequente melhoramento de ambos, nunca esquecendo o "método" que preside a loucura.

A perspectiva não só relativiza como marca a situação do discurso, pela diferença de códigos e regime de jogo dos contrários. Daí a relativização de situaçōes mesmo nas escrituras fechadas e rìtualizantes.

E, neste sentido, o código celeste, principalmente a lua'1, 6 uma inclusão simbólica da concepção simétrica cíclica de existência, além de ser um arquétipo da dialética construção/destruição.

Também a parábola do bêbado olhando o céu, no Capítuo XILVI, é uma inclusão simbólica com valor de índice explicitado do conceito de perspectiva em que o olhar e o ser olhado cria uma espécie de "jodo do siso, com certo ar de magestades rivais e tranquilas", poic assim como o céu não há de cair em cima do bêbado, este não poderá escalá-lo.

A perspectiva é também força motivadora de ações na medida em que o gesto se reveste de duplo significado: o exterior ou da aceitação pública e o interior ou o do ser.

Esta dialética ser/ parecer, resulta na relativização das formas de vitória explicadas na oposição entre a aceitação pública e a realizaçāo pessoal.

Eis porque Quincas Borba enfatiza a consagração pública através da trajetória em direção a determinados espaços.

11 "Lhomme s'est reconnu dans la vie de la lune non seulement parce que sa propie vie avait une fin ezmm? calle de tcus les organismes, mais surtout, parce qu'elle rendint valable, du fail ds lo "nouvelle lune" sa propre soif de regeneration, ces espoirs do renaissance". (ELIADE, Mirceia. Trails d'Historit des rsligions. Paris, Payot, 1970 p. 143 ). 
Nesta obra o espaço fechado, passa para um segundo plano, em favor das ruas, verdadeiros espaços-paleos da consagração definitiva.

Nas ruas desfilam os vitoriosos coupés, o coche imaginário, encontram-se "os amigos do trânsito, que (Rubião) amava tanto, que - cortejavam tanto, davam-lhe a vida um aspecto de viagem" ( $p$. 207).

Os bailes, as decoraçōes das casas sustentadas pelo critério de não identificação com o dono, mas pelo inventário de objetos para serem olhados como matérias de preço, situam-se na mesma isotopia do espaço exterior privilegiado em detrimento da intimidade.

A primeira cena do livro em que é descrita a casa de Rubião exemplifica a incidência da exterioridade sobre o espaço fechado.

De sua "sala de Botafogo", fitando a enseada, através da janela, Rubião se vê cercado de objetos destituídos de função e significado intimos:

".... ia disfarçadamente mirando a bandeja que era de prata lavrada. Prata, ouro, eram os metais que amava de coração não gostava de bronze, mas o amigo Palha lhe disse que era matéria de preço, e assim se explica este par de figuras (...) Vendo as gravuras inglesas que pendiam da parede por cima dos dous bronzes, Rubião pensou na bela Sofia, mulher de Palha, deu alguns passos e foi sentar-se no pouf, ao centro da sala, olhando para longe...

- Foi ela que recomendou aqueles dous quadrinhos quando andávamos os três, a ver cousas pa. ra comprar" (p. 114).

A impressão do domínio do mundo ("desde os chinelos até o céu tudo entra na mesma sensação de propriedade") é sustentada no inventário de objetos, restaurando o sentido (etimológico) de objec. tum.

O desequilibrio interno ("sentia que não era inteiramente feliz") resulta da necessidade de se impor pelas coisas, coisas não desejadas, mas necessárias ao equilíbrio social.

O conceito de objetos kítsch não só é explicado pela ausência de significado de tais objetos, mas na inversão de funcionalidade em favor gratuidade tornada necessária pela aceitação social. 
Cercado de gravuras inglesas, poufs, objetos de bronze, vestindo chinelos de Tunis, Rubião traduz o sistema de ambiguidade instaurado no relacionamento personagem-espaço-objeto traduzido em um mecanismo social tornado um elemento interno e ativo da cultura.

Em tal espaço jamais poderá ser encontrada a cumplicidade do sonho e de intimidade que preside a dialética mundo/casa, apontada por Bacherard.

O espaço de casa, deixa de ser o nāo eu que protege, abriga e mesmo a ação de governar a casa é deturpada pela imposição social. Pela "necessidade de ter criados brancos": um francês reina na cozinha e o espanhol dá ordem, enfim, é o código social que comanda, "por mais que dissesse", "nem pode deixar", etc.

Esta "lua de mel com a grandeza" / insafisfação pessoal tem sua simetria no capítulo XLXI quando Sofia, já na casa do Flamengo, dona da nova situação, reflete a não identificação com o espaçocasa através do devaneio que a projeta para lugares distantes.

A canoa obedecendo aos remos dos homens, no primeiro caítulo é um índice' explicitado fela ironia em que se situam os donos da casa, ora tomados pela impressão de domínio do universo, ora insatisfeitos pela não identificação com a nova propriedade.

Esta colocação encontra apoio na utilização insistente do verbo olhar, substantivos olhar e olhos'2 empregados respectivamente em vários sentidos posse, consagração, janela da alma.

Em seus percursos todos querem ser vistos e aprovados, o olhar consagra o olhar é propriedade e recomenda o proprietário, o que nos remete sentido de valor visual, empregado por Berenson, como valor sustentado na aparência, por oposição ao valor táctil ligado à forma "aspecto das coisas visiveis que intensifica a vida"13.

Há ainda que ressaltar a disposição das cenas internas privilegiadas pela descrição de detalhes espaciais, todas elas marcadas pela presença de um janela aberta, permitindo a fusão do exterior com o interior.

Apenas dois espaços de Quincas Borba privilegiam a identificação personagem-paisagem: o passeio a cavalo de Carlos Maria no

12 Ainda que o simpies centagam das rcferénsizs nis tenhs sentido sem uma cimpsraçzo convém natar as 180 vezes em que aparece olhcs. 9 vezes olhar e 78 vezes verbo olhar.

13 BERENSON, Bernard. Estética - história en las artes visuales. Buenos Aires, Fondo do Culiura Economica, 1956. p. 56. 
Engenho Novo e a passagem na chácara de Dona Fernanda, podendose, ainda, incluir a rápida sensação de Rubião quando do passeio à Praia Formosa e volta a Barbacena:

"Era ela, era Barbacena, a velha cidade natal ia-sethe desentranhando das profundas camadas da névoa" (p. 332).

Estas observações explicam o regime metonímico de indicação das moradias a partir do bairro em que estão localizadas as mesmas, realizando a seguinte operação simétrica:

$$
\text { a bairro }=\text { moradia }=\text { posição social }=\text { dono }
$$

As moradas como Botafogo, Santa Tereza, Flamengo, Tijuca, etc. são pelo que representam na geografia urbana do status, indices da vitória ou da decadência social.

Assim, o percurso da vitória e da degradação pode ser seguido pela indicação destas menções, havendo uma perfeita homologia entre elas e a cadeia horizontal das ações:

$\begin{array}{ccc}\begin{array}{c}\text { Trajetória de } \\ \text { Rubiāo }\end{array} & \begin{array}{c}\text { Trajetória de } \\ \text { Palha }\end{array} & \begin{array}{c}\text { Trajetória de } \\ \text { Major }\end{array}\end{array}$

Barbacena

Botafogo

Santa Tereza

Dous de Dezembro

Rua do Príncipe

Flamengo

Barbonos

Barbacena

Botafogo

Cajueiros (Rua da

Princesa)

As ruas por sua vez são índices de situações comprometedoras (Rua da Harmonia): da decandência (Rua do Príncipe, Cajueiros) ou dos encontros consagradores.

Delirando Rubião desfila no coche, através de paços imaginários, vitoriosa, Sofia atravessa as ruas com sua carruagem, despertando inveja, pois "o transporte adquire as cores de certas camadas sociais traduzindo suas linhas e exteriores, vivendo os dramas, as aflições e as alegrias do indivíduo", realizando a simetria entre a posição social e o meio de condução, não esquecendo que o coche como transporte de privilégio do imperador só caberia no sonho de um louco:

"Sofia de coupél Fingiu que não via" (p. 267).

... passar de carruagem que era sua, entre parênteses. Acabara a lua de mel de grandeza, agora

14 FAORO. p. 49. 
torcia os olhos du:amente para o lado, conjurando, de um gesto definitivo, o perigo de alguma hesitação" (p. 274).

... "olhos cheios daquela curiosidade (...) dos demais havia o coupé do Rubião, que se destacava das cabeças velhas $(.$.$) ao entrar o coupé ouviu$ (...) parece que é senador ou desembargador" ( $p$. 229).

"Olha mandar-te-ei um dos meus coches, novo em folha" (p. 326).

Confirmando as palavras do narrador de que "há entre o céu e a terra mais ruas do que sonha a (tua) filosofia", as ruas e as coisas funcionam como indices explicitados do processo de degradação ou melhoramento.

- Espaço-zona urbana tomado como valor social manifesta de forma definitiva a vitória alcançada no percurso das personagens; enquanto Palha inaugura os seus salōes na mansão (restaurada) em Botafogo, a casa de Rubião ein ruinas é o retrato de seu antigo dono.

Esta simetria global da obra e a repetição de situações (às vêzes investidas), através do percurso por determinado espaço, é assim avaliada pelo narrador:

"Era a mesma situação de Barbacena mas a vida, meu rico senhor, compōe-se rigorosamente de qua. tro ou cinco situaçōes que as circunstâneias variam e multiplicam" (p. 326).

Aprofundado o significado da simetria, observaríamos as suas intimas relaçōes com o tópico da ingrałidão humana, que tem no episódio da Rua da Ajuda um dos exemplos privilegiados.

Se de um lado a posição do vencedor ou vencido determina um comportamento bajulador ou ingrato, a relatividade da ingratidão explica-se pela própria indiferença e caráter cíclico-simétrico da existência:

"Não é preciso estar embriagado para acender um charuto nas misérias alheias. (...) ninguém em seu juízo faz render o mal dos outros, não contando o respeito que aquele bebado tinha ao principio da propriedade - a ponto de não acender o charuto sem pedir licença a dona das ruinas" (p. 250). 


\section{Espaço e os objetos ao nivel da ação}

Ao nivel da ação, na cadeia sintagmática da narrativa, o(s) espaços(s) $\epsilon$ as coisas não funcionam como elementos autônomos.

Assim, um primeiro grupo de predicados; se encontrar, se relacionar, ser aceito, olhar/ser olhado, posar, todos eles ligados à ascensão e aceitação social, constituem um primeiro grande nó sintagmático a amarrar o espaço e objetos.

Vale dizer estes são elementos da comunicação no relacionamento, o que pode ser comprovado pela já verificada relação simétrica entre a topologia urbana da personagem, os objetos de sua propriedade e seu posicionamento na escala social.

Como portador de uma mensagem o objeto só adquire significação pelo gesto, passando a ser, portanto, um canal de informação.

O início do relacionamento social de Rubião é marcado pela presença de sua casa, também espaço adjuvante de Palha e Sofia no processo de sedução ("amigo Palha prestou grandes serviços ao Rubiäo guiando-o no gosto") que passam a recomendar ao amigo o valor dos objetos.

Para a casa de Rubião se dirigem os amigos de primeira hora, Carlos Maria o admirador de charutos, "os outros convivas seguiram o primeiro, escolheram charutos e os que ainda não conheciam - gabinete admiraram os móveis bem feitos e bem dispostos" ( $p$. 274).

Por um processo de troca Rubião também se afirma ao ser olhado e usado:

"Recompunha mentalmente o almoço prato a prato, via com gosto os copos e o seus resíduos de vinho, as migalhas esparsas (...) dava um olhar à casaca do criado". (p. 143).

Os novos convivas que se introduzem pela lisonia à propriedade de Rubião também se reconhecem mutuamente pelo traje, pelos objetos como portadores de informação: "viu também que a roupa era fina, sem luxo, e que os pés estavam mal calçados".

A ascençāo gradativa de Palha, por sua vez, é comunicada pelos seus objetos, conforme avaliou Rubião ao lançar "olhos aos móveis, porcelanas, cristais, reposteiros".

Palha, no entanto, comunicará sua vitória definitiva exibindo a 
mulher que sempre adornou com jóias e vestidos caros não deixando de se preocupar com objetos para a casa "mormente se eram invenção recente".

O corpo de Sofia é neste processo um objeto adjuvante de Patha, portador da força de sedução e alvo do olhar de admiração de toda sociedade.

\begin{abstract}
"Estava deslumbrante. Ostentava, sem orgulho, todos os seus braços e espáduas. Ricas jóias, o colar era ainda, um dos primeiros presentes do Rubião, tão certo é que nesta guerra de atavios, as modas conservam-se mais". (p. 330).
\end{abstract}

Esta necessidade de se afirmar pelas coisas, pela coleçāo de objetos homólogos à classe social explica esta presença de Sofia como objectum (que existe fora) conquistando e criando seu espaço.

Destas observaçōes se conclui que a relação personagem-espaço-objeto não é passiva e dócil. A personagem tem nos objetos os seus adjuvantés e cúmplices, porém e'es devem ser conquistados, seduzidos na mesma proporção que seduzem "ela acabou gostando de ser vista, muito vista".

Assim o relacionamento das personagens-espaço-obejtos, vistos a partir de um ponto de chegada para um ponto de partida, envolve o seguinte grupo de predicados: seduzir, manipular, dissimular, éiminar, vencer.

E aqui que verificamos a trajetória por um espaço inverso entre o vencedor e o vencido.

Os movimentos no espaço ligados à sucessão de objetos adquire uma forma dramática como se ao levantar a cortina a scène indicasse o novo curso da narrativa.

Donde a possibilidade de demonstrarmos que a sifuação dos objetos e espaços nas isotopias ser/parecer implica em dois tipos de isotopias espaciais. Uma primeira do espaço décor, décor aqui tomado não apenas pelo que remetem os verbos decôro (ornar, formosear) e decoro (ornar, compor, formar), mas a partir das implicações décor - décórum (decência) décórus (decoroso, decente. Mag. num iéxicon latinun et lusitanuns. $4 .^{\circ}$ ed. 1833).

Ora, a noção de ornar, compor aliada a decoroso não poderia pressupor ao nivel gnoseológico uma criação de um sujeito transcendental, mas o resultado de um código de normas psicofisiológi- 
cas do homem e da sociedade. Tal acepção espaço décor, lugar convencionalismo fatalmente opor-se-ia ao ser.

Nossa opção está sustentada na relação ,décor-convenientia agora no sentido empregado por foucault, "como vizinhança dos lugares", "semelhança de lugares", enfim espaço onde "na vasta sintaxe do mundo os seus diferentes ajustam-se aos outros (...) - homem com tudo que o rodeia" o que evidentemente parte da explicação da trama semântica ligada a um entendimento do mundo "como conveniência universal das coisas"1s.

Na segunda isotopia espacial, espaço scène (representação, decoração de teatro, Littré) é que estariam situados os componentes de um comportamento posado, exterior.

O sentido da teatralização espacial em Quincas Borba é meIhor explicitado no capítulo XX do primeiro texto da obra publicado em A Estação, que no texto eleito para edição crítica, (corresponde ao capítulo 1), quando Rubião exclama ao observar o cenário que o cerca: "Theatro... Theatro... murmura elle aqui se podia representar muito bem um idylio piscatório".

Definida a terminologia adotada obtem-se:

Espaço décor

Objeto funcional

objeto manipulável

objeto pensado

espaço íntimo

espaço proteção

o dentro
Espaço scène

Kitsch

objeto sedutor

objeto "pensante"

espaço exterioridade

espaço degradaçāo

o fora

\section{$S E R$}

PARECER

O que também nos permite situar Machado de Assis entre os autores em que a presença de objetos parece motivadora e motivada por certos tipos de ação, opondo-se à uma tradição romanesca que atribui ao objeto papel providencial ${ }^{16}$.

O "método da loucura", neste processo, reside no movimento acelerado e desproporcional da força e da presença do objeto.

16 E o que observa Henri Lafon em relaģo os romances de Crébillon, so aproximálos de um tipo do narrativa em quo o cbleto motiva a açäo ainda que permaneça tributf́rio da tradição romancesca do objel-quiprocos.

15 FOUCAULT, Michel. As palayras - as coisas. Lisboa, Martins Fontes, s.d. p. 35-6. 
Considerando apenas o processo de sedução de Rubião, o "objeto" que melhor caracteriza o ponto de chegada e o ponto de partida é, ainda uma vez, o corpo de Sofia.

Ao insistir que Sofia está aqui toda, o autor parece perceber a extensão da presença desta personagem.

O olhar de Sofia comparado "A lanterna de uma hospedaria que não houvesse cômodos" é um índice de sua função de sedutor.

A.o lengo da obra, além da força do olhar, Sofia vai criando seu espaço como "algo que se oferece à vista", "lançado ao encontro" através de uma presença em que as formas e os gestos passam à categoria de elementos físicos ${ }^{17}$.

As descrições pormenorizadas de seus gestos, detalhes físicos, de seu olhar totalizador vão insistindo na sua situação de "coisa disposta", manipulável.

Porém seu corpo é o objeto que seiduz, que conquista o espaço vital e textual, hipnotizando a vítima que acaba eliminada pela desproporção de seu sonho.

Sofia se oferece como espetáculo e acaba espectadora distante da tragédia de Rubião.

\section{CONCLUSÃO}

Funcionais e indispensáveis, os objetos e o espaço traduzem o rito social, dispōem sobre o relacionamento das personagens, regulamentam seus desejos e sua comunicação.

17 Que ombro! Parecen de cero, tāo lisos, tão brancos! Os braços 1ambém; os braços! Que bern feitos “ (p. 114) "A bocs parece mois fresca, ombros, mãos, braços são melhores, e cla ainda as faz b́timos por meio de atitudes e gestos recolhidos(...) Traja bem, comprime a cintura e o tronco no corpinho de tins de castanha" (p. 147).

"Rubiöo admirol-lhe ainda ums vez a figuro, o bruto bem ta!hado, estreito embaixo, largo em cime, emergindo das cadeias amplas cemo ums braçada de falhas sai de dentro de um vaso" (p. 150) "Trojors de azul escuro, mui decofada(...) os braşos nus, cheios com uns tons de ouro claro, ojustarim-se as esplduas e os seios tāo acostumados ao gbs do saläo" (p. 195). "Mas Palha buixavo os olhos até ao resto da perna cnde pegara com o cano da botal De feito, eia um belo trecho da nutureza, a meia de seda mostrara a perfeiça do contorno" (p. 279) 'E is tirunda os grampos deitando-os num vaso de cristal, os cabelos caiam-lhe sobre os ombros mal cobertos pela camisols" (p. 199).

"O luto is-the muito bem, e o vestido parecia uma lua, sentada via-se-lhe metade do pe, sapato raro, meia de seds, cousas todas que pediam misericordia e perdão " (p. 231)

"Sofia bateu ccm o leque no lado direito do vestido para abaixar e compor; depois levantou os braços sasudindo as pulseiras de vidro preto, finalmente pousou sobre os ioelhos (p. 232). Obs. optamos pelas citaçōes - levantamento como nota de rodapé a fim de introduzir no corpo do trabalho apenss as citaçōes essenciais, o que evila certo tipo de trabalho, sustentado em "aspos" ou pardfrases. 
Espaço e objeto tornados signos motivados pela marca da situação do discurso, que evidencia pela diferença o manifesto e o dissimulado, permitem que se vá mais longe na indagação da ideologia do autor.

E quando encontramos constatada a experiência de "desconcerto" apontada por Roberto Schwarz ${ }^{10}$ ao analisar a visão cética de Machado de Assis quanto à introdução das idéias burguesas no Brasil.

Esta experiência do "desconcerto" diante do espaço e objeto delatada pela ficção machadiana é, segundo elé, especificada num mecanismo social na forma em que ele se torna elemento interno e ativo da cultura.

Se o interesse pelas coisas é o resultado da experiência burguesa, em Quincas Borba o autor foi mais longe ao traduzir o mecanismo anacrônico, o desproporcional e contraditório da experiência brasileira.

Sofia lendo a Ruvue des Deux Mondes, Rubião com suas estatuetas de bronze e chinelos de Tunis traduzem não só o papel assumido pelo espaço e objeto na ideologia burguesa, mas o sistema de ambiguidade no uso local do ideário burguês.

- Napoleão com o qual Rubião se identificará em seus delírios não poderia ser o das batalhas, mas o da ostentação dos salōes, parodiando assim a fusão/confusão das impropriedades do pensamento burguês na cultura brasileira.

\section{RESUMO}

O propósito da análise cio papel assumido pelo espaço e objetos em Quincas Barba está centrado na tentativa de portir do levantamento dos dados significantes para questionar a estrutura do cb:a como reveladora da tensāo resultante da introduçäo do novo papel assumido pelo objoto no rito da scciedade industrial, mais particularmente, na experiência do "desconccrto" com que tal sistoma penetrou no Brasil.

Inicialmente procurarmos anălisar o espaço do livro e o livro como objeto, vale dize: a consciéncia de corealidade e a marca do lugar do discurso, tornada fundamental pelo que esta cemporta na recusa do código.

A partir do aprofundamento do percu:so espacial das personagens, do papel da simetria o da perspectiva oblivemos no a do tema profundo do vitória a linha cendurora da relativizaçāo, o que privilegiará o jogo de isolopias ser/porecer.

18 SChWARZ, Roberto. Idéios fora do lugar. Estudos Cebrap cezrap, Sáo Paulo, (3): 151-61, jan. 1973. 
Através de constatação quintitstiva verificamos que Quincas Borba é uma obia em que o espaço aberto ocupa papel fundamental, permitindose atribuir à ruas, bairros c objectos o papel de sinédoque do sujeito na medida em que são índices do processo da degradaçáo ou melherarr:nto. $O$ objeto perdendo seu caráter funcional ao ser encarado como canal de informação do status social torna.se kitseh, o que apoiará a proposta da releşōo isorópica espaço décor lconstituido de objetos funcionais, espaço de intimidado e proteçāol espaço seàne (comportando objetos kitssh, com função ora adjuvanic o:a oponente de aco:do com as leis da exte:iaridadel.

Conc'uimos a partir de tais colccuşöes que Quincas Borba dalata um mesanismo sscial no forma em que cste assume o papel de clemento intimo da cultura.

\section{RESUME *}

Le but da l'analyse du rôle assumé par l'espace et par les objets dans Quincas Boiba est centré dans l'essai de partir da lo levée des dennées signifiantes pour matire en questicn la struciure de l'oeuvre comms révélatrice de la tension résultanta de l'intrcduction du ncuveau rôle assurré far l'cbjet dans le rite de la société industrielle mais particulièrement dans l'experience du "disaccord" avec lequel un tel système a pénétré dens le Brésil.

Ncus avons cssayé d'abcrd d'analyser l'espace du livre ef le livre comme objet c'est à dirs la conscience d'une coréqlité et la ma:cus de la place du discours rendue fondamentale pour ce que celle ci comporte dans le refus du code.

A partit de l'aproicndissement du parcou:s de l'espace des personnages du röle do la symétrie ef de la perspective nous avens obtarmu du et par le theme piofond d la victoiro le fil cenducteurs de la relativité ec que privilégiera le jeu des isotopies êtrel paraitre.

A travers la constation quantitative neus verifions que Quincas Boiba est unz ocuvre dans laquelie l'espace cuvert johe un rôle fondamental permettant d'atribur aux rucs faubourgs et aux objets le rôle de synédoche du sujet dans la mesure ou ils sont des indices du procédé désagrégation ou d'amélioration. L'objet en perdant ses carac:ćristiques fonctionnelles dans le moment ou il est envisagé comme canal d'information du status sccial devient Kitsch ce qu' appuiera la proposition de la ralation des isotoples cspace/décor lconstitué par les objets fonctionnels espace d'intimité et de protecticn) espace/scène (compcrtant cies cbjets Kitsch ovec une fonction lou: à tcur adjuvante cu opposante d'accord avec les lois des apporences extérieures).

Nous coneluons à partir da tels emplacements que Quineas Borba dénonce un mécanisme social dans la mesure où celui-ci assume le rôle d'élement, intime de culture.

\section{REFERENCIAS BIBLIOGRAFICAS}

AUERzACH, Érich. Mimesis; a representaçāo da realidade na lits:afura ocidental. São Pauls, Peifectiva, 1971. 496 p. (Estudos, 2)

BARTHES, Roland. Reland Barthes par Roland Barthes. Paris, Sevil, 1975. 191 p. (Écrivain de teujours. 96)

- Versão de Ivelise de Araúio Szaniawski. 
EENSE, Max. Estótica; sansiderasines matafisicas sobre lo belo. Busnos Aires, Nueva Vision 1973. 85 p. (Colezción Ensayos Arte y Estética)

BERENSON. Bernard. Estótica e histária en las artes visua'es México, Fondo de Cultura Econômica, 1956. 270 p. (Breviários, 115)

EREMOND, Claude. Logique du recit. Paris, Seuil, 1973. $350 \mathrm{p}$.

ELIADE, Mircea. Traitê Trité d'histoirc des réligions. Paris, Payot, 1970.

FAORO, Raymondo. Machado de Assis: a pirámide o o trapésio. Sio Paulo, $\mathrm{Na}^{-}$ cional,, 1974. 5C5 P. (Brasiliaria, 366)

FOJJCAULT, Mi=hel. As palayras o as coisas Lisboa, Martins forites, s.d.

GREIM.AS, A. J. Semântica estrutural. São Paulo, Cultrix, 1973. 330 p.

LAFON, Henri, Les décors of les choses dans les romons de Ciébillon. Poótique, Paris, (16): 455.65, 1973.

LUKÁCKS, George. Ensaios sobro litorafura 2 ed. Rio de Janeiro, Civiiização Brasilci.s. 1963. 249 p. (Bib.ioteca do leitor moderno, 58)

MACHADO DE ASSIS, Joaquim Maria. Quincas Borba, Rio de Jineiro, Instituto Nacional do Livro, Comissão Machado de Assis, 1969. 335 p. LObras Completas de Machado de Assis, 7l.

- - - - - Apéndice. Rio de Janeiro, Instituto Nocional do Livro, Comissão Mashado de Assis, 1970. 242 p. (Obras Completas de Moshado de Assis, 7 ).

MATTOSO CÃMARA JR., Joaquim. Ensaios machadiancs; língua e estilo. Rio de Janciro, Livraria Acadêmica, 1962. 173 p.

MENCONÇA, Antonio Sérgio. Por uma teoria do simbólico. Petrópolis, Vozes, 1974115 p. (Coleção Mestrado, 2).

RIEDEl, Dirce Cortes. Metáfora; o espelho de Machado de Assis. Rio de Janeiro, F.onzisco Alves, 1974. $155 \mathrm{p}$.

SEHNARZ, Reberto. Idéias fora do lugar. Estudos CEBRAP, Säo Paulo, (3): 151.61, i $\geq$. 1973

SéMIOLOGIA dos objetos. Patrópolis, Vozes, 1972. 196 p. (Novas perspectivas em comunica̧̧āo, 4). 